\title{
De la "indiferencia "
}

\section{al "tercer grado de humildad". Notas para una cristología de libertad}

\section{José Ignacio González Faus, Facultad de Teología de Barcelona.}

Estas breves notas intentan poner en contacto el Principio y fundamento de los Ejercicios, con la Nota sobre los "tres grados de humildad". Más exactamente, intentamos relacionar la apelación a la "indiferencia" que clausura el Principio y fundamento, con el "tercer grado de humildad" que culmina la segunda semana.

Inculturándolos en la mentalidad moderna, se puede hablar de ambos pasajes como de una llamada a la libertad, o de una "liberación para la libertad" (Gal 5,1). Pero de tal modo que, desde el Principio y fundamento hasta el tercer grado de humildad, hay toda una evolución o "cristificación" de la libertad, que proviene del encuentro del hombre con Jesucristo a lo largo de los Ejercicios.

El tercer grado de humildad vendrá a ser entonces la "reconversión" cristológica o el "procesamiento" cristológico del texto de la indiferencia.

\section{Presupuestos antropológicos}

1. El hombre llamado a la libertad

"El hombre es criado para alabar, hacer reverencia y servir a Dios Nuestro Señor, y mediante esto salvar su ánima; y las otras cosas sobre la haz de la tierra son criadas para el hombre y para que le ayuden en la prosecución del fin para que es criado. De donde se sigue que el hombre tanto ha de usar dellas, cuanto le ayuden para su fin, y tanto debe quitarse dellas, quanto para ello le impiden. Por lo cual es menester hacernos indiferentes a todas las cosas criadas, en todo lo que es concedido a la libertad de nuestro libre albedrfo....; en tal manera que no queramos de nuestra parte más salud que enfermedad riqueza que pobreza, honor que deshonor, vida larga que corta, y por consiguiente en todo lo demás. solamente deseando y eligiendo lo que más nos conduce para el fin que somos criados" (Ejercicios, 23). 
En un primer momento, estas líneas no resultan demasiado atractivas. Dan la impresión de que, con la excusa de que el hombre es de Dios, le someten a una prueba y le imponen una serie de renuncias dolorosas que incluso le prohíben el deseo. Es verdad que san Ignacio sólo evoca ese programa "en lo que le es concedido a la libertad" con lo cual ya parece concebirlo como una cualidad de ésta. Pero no impide que el lenguaje resulte impositivo ("debe quitarse", "ha de usar"). Y encima, semejante programa pretende afirmarse a partir de una argumentación puramente racional y deductiva ("de donde se sige", "por lo cual", "por consiguiente"...).

¿Es esa la intención del Principio y fundamento? Hay que reconocer que semejantes lecturas del Principio y fundamento se han hecho más de dos veces, y pueden estar abonadas por aquella mentalidad teológica de la vida como simple "estado de prueba", que parece haber marcado casi todo el ambiente en que se movió Ignacio'.

Si, más allá de las insuficiencias del lenguaje, intentamos hacer una nueva inculturación de la experiencia antropológica que parece haber movido a san Ignacio al redactar el Principio y fundamento, podemos encontrarnos con paráfrasis de este tipo, que no le son en absoluto infieles:

El hombre puede ser libre. Puede serlo porque tiene un norte. $Y$ sólo un norte puede unificar la pluralidad constitutiva del ser humano, impidiendo que una de sus dimensiones esclavice a las otras (vg. la dimensión material a la espiritual, o viceversa; la dimensión individual a la comunitaria, o viceversa; la inmediatez al largo plazo; o la eficacia a la gratitud y viceversa...).

Huelga añadir que, si el hombre puede ser libre, entonces debe serlo (al menos debe intentar serlo). Pero ahora es más importante comentar nuestra reformulación.

A pesar de la seriedad con que habla del pecado, san Ignacio nunca creyó sin más en la "maldad" de los hombres, al estilo de tantos discursos eclesiásticos. Sabía más bien que la inmensa mayoría de nuestras reacciones malas están provocadas por falsas esclavitudes: miedos injustificados, angustias desproporcionadas, necesidades inmaduras de seguridad, anticipaciones ansiosas, enquistamientos en modos relativos y vértigo de salir de ellos... Todo eso hace reaccionar al ser humano con agresividad o con poca generosidad.

Pues bien, la "indiferencia" del Principio y fundamento no es más que la libertad de estas falsas esclavitudes. Aunque las resonancias del término ignaciano son hoy más bien negativas, sin embargo, es un término emparentado tanto con la apatheia (ideal antropológico de los estoicos y de los padres griegos), como con la espiritualidad del oriente, y su eliminación del deseo.

Pero conviene notar que, en el texto del Principio y fundamento, la indiferencia no brota de la anulación del deseo, sino de su fuerza: "solamente desean- 
do". El quicio de la argumentación reside precisamente aquí: la persona tiene un fin (meta del deseo); y porque tiene un fin puede ser libre: ya que libertad no es sino la idoneidad para el propio fin y la propia identidad.

Este trazo argumentativo es el que nos interesa ahora. Quizá convenga aclarar también, aunque sólo sea en un inciso, que el resto del vocabulario sobre el fin del hombre (alabanza, reverencia, servicio a Dios, salvación del alma), puede crear dificultad o no, según se haga de él una lectura "religiosa" o una lectura bablica. Limitándonos a esta última, será suficiente recordar que, bíblicamente hablando, el servicio de Dios es la causa del reino, la alabanza a Dios es la vida plena del hombre (san Ireneo), y la reverencia máxima a Dios es nuestro respeto por su preferencia para con los pequeños (ver. Jesús en Lc. 10, 21). Y que la "salvación del alma" no es simple premio extrínseco reservado a la otra vida (otra vez la teología del "estado de prueba"), sino plena realización de la persona (que trasciende ciertamente a esta dimensión).

Una vez hecha esta aclaración se comprende mejor el punto de partida ignaciano.

El hombre pues tiene un fin, en el que coinciden una dimensión teológica y otra antropológica. La realidad de este fin es la única que puede volver al hombre libre ante las cosas. Porque las cosas no son sino medios para ese fin.

Esta formulación resulta, en la práctica, tan exigente como la del texto de los Ejercicios. Quizá resulta, en cambio, más comprensible (o menos hosca), porque la hemos inculturado en nuestra mentalidad, simplemente.

Pero es a partir de ella como comienzan los problemas.

\section{La libertad, excusa para lo inhumano}

Ese fin del hombre resulta prácticamente imposible para él, porque es un auténtico esclavo en un mundo de esclavos. Aquí comienza la tragedia de la existencia humana: si el norte del hombre es inasequible, la libertad se convierte con ello en un mal sueño utópico.

Esta es la función de la primera semana. $O$, más exactamente habría que decir que su función es descubrir al hombre como rescatado de esa situación de esclavitud. Pero, para nuestro objetivo en estas páginas, baste con la primera formulación: la libertad imposible.

Lo que imposibilita esa libertad del hombre es la historia del mundo como historia del mal (del "primero, segundo y tercer pecado": EE 45), y el desorden implantado en el mundo. Ambas cosas conectan con el desorden implantado en el interior de cada uno, y lo posibilitan. La marcha de la historia, el funcionamiento del mundo y del hombre ("las propias operaciones": $E E$ 63), son contra- 
rios, o tienen demasiados elementos contrarios al reinado de Dios, a la humanidad del hombre y a la vida de los pobres. Esos tres factores han crucificado al hombre.

En este contexto, la libertad del hombre no sólo es muy difícil, sino que ha de verse rechazada por el mundo. Si el mundo se estructura como anti-reino, la acción por el reino pedirá aún una más suprema libertad frente a todos los golpes que esa acción puede atraer: deshonor, dolor, persecución, ¿vida corta quizás?... Y puede atraer esos golpes porque es una acción, a la vez, molesta y desarmada. "Combatir todas la injusticias activamente y no violentamente", proponía Gandhi en una famosa película. Pero si uno las combate activamente resultará incordio, y si las combate no violentamente se encontrará indefenso. El resultado y el nivel de libertad que ahora se le pide al hombre, esta gráficamente descrito en otra impresionante secuencia de aquella película: caminar hacia el lugar al que uno tiene derecho, pero que la policía prohíbe y vigila con armas, para recibir el golpe al llegar al alcance de esa policía, hasta ser retirado herido, y asistido por los amigos. Aquella dura secuencia de la película es una parábola gráfica de la imposible libertad que ahora se le pide al ser humano: lo que la imposibilita ya no son las falsas esclavitudes del propio yo, múltiple y disperso, sino la falsa libertad de los propios contextos, negadores de justicia para los oprimidos, de paz para lo hombres y de armonía para la creación.

Pues bien, si en este contexto alguien anuncia que la libertad es posible y que puede ser reconquistada o - al menos - puede ser reabierto el camino hacia ella, ¿cómo no habría que seguirle? No hará falta para ello ninguna intimación y ningún imperativo, sino sólo que se tenga "juicio y razón" (EE 96).

Aquí comienza la trayectoria de una cristología de libertad. Hay una mirada benevolente de Dios sobre "toda la haz y redondez de la tierra y todas las gentes en tanta ceguedad" ( $E E$ 106). Una mirada que allí donde esas gentes no hacen sino "herir, matar", etc., (108), decreta "hacer redención del género humano" (107). Y esa redención no se hace destrozando al mundo, sino metiendo a Dios en él ("obrando la santísima encarnación": 107).

Sin este último punto no es posible comprender el "tercer grado de humildad". Porque la discusión sobre dónde hay mayor gloria de Dios, es para el hombre una discusión muchas veces insoluble y escolástica. Lo que la encamación aporta sobre esa pregunta es que Dios se ha hecho hombre para que lo encontremos y honremos en los hombres, no en los templos o en el cielo o en las nubes. Nosotros, en cambio, preferimos hacer de la encarnación "un dogma" que le afecta sólo a Dios, y así seguimos buscándolo en las iglesias etc., y lo dejamos en los hombres. Repito que, de este modo, no habrá manera de comprender el tercer grado de humildad que es, en realidad, un grado supremo de libertad.

Pero, aceptado esto, aquí comienza el proceso que lleva hasta el final de la segunda semana de los Ejercicios, y en el que la "indiferencia" del Principio y 
fundamento se va a convertir — filtrada cristológicamente — en tercer grado de humildad.

\section{La cristificación de la libertad}

\section{Por qué se hace necesaria}

Esta nueva manera de "procesar" la libertad brota de una constatación que para Ignacio fue central en la lenta gestación de su espiritualidad. Cabría formularla como la constatación de que el realismo es muchas veces contrario al reino de Dios.

No me estoy refiriendo al realismo de la pecaminosidad humana, sino simplemente al de la "autonomía de lo creado". Lo que parece imposibilita el reinado de Dios no es sólo la maldad del hombre (la cual puede ser convertida), sino la densidad misma de lo real.

Y ello plantea, necesariamente, el problema de las "mediaciones" del reino: este ha de ir acercándose poco a poco, no en su plenitud inmediata, sino en la medida posible en cada momento. Y esta medida hay que saber encontrarla, porque las simples buenas intenciones pueden pavimentar muchos infiernos, queriendo buscar el reino. La utopía, por tanto, sólo podrá abrirse paso a través de mediaciones siempre lentas e insuficientes, pero que son las únicas posibles. La instiución ahoga al carisma que tenía que encarnar, y la razón quita sentido y suelo a los fervores del seguimiento a los que debía concretar. La densidad de esta tierra no admite demasiados idealismos evangélicos. Y esto antes ya de toda consideración sobre la pecaminosidad humana.

Todo ello es absolutamente cierto. Innegable parece también que san Ignacio vivió buscando la mayor síntesis posible entre ambos elementos opuestos. Y en él sería fácil hacer una lista de textos atentos al realismo de lo posible, y otra de textos abiertos a la locura de lo místico.

Pero, si todo ello es cierto, es igualmente exacto que el realismo "no es neutral" (como suele decirse hoy respecto de la ciencia, tan necesaria también por otra parte). El realismo favorece casi siempre al egoísmo humano, y puede bloquear asi "la salida del propio amor, querer e interés" (EE 189). Y los hombres tendemos entonces a utilizar el realismo (para decirlo con la expresión paulina del Gal 5, 13) "como excusa para el egoísmo".

Pues bien, en este contexto, el tercer grado de humildad viene a ser como una especie de estratagema cristológica para evitar esta dura ley de la vida. Veamos cómo.

\section{La afectividad en servicio de la libertad}

Quiero recordar antes que se trata de un texto sugerido expresamente al "en- 
trar en las elecciones, para hombre affectarse a la vera doctrina de Christo Nuestro Señor" (EE 164, los subrayados son míos, y llaman la atención sobre el contexto de afectividad y decisión). Veamos ahora el texto:

"La tercera es humildad perfectíssima, es a saber, quando incluyendo la la y 2as, siendo igual alabanza y gloria de la divina majestad, por imitar y parescer más actualmente a Christo Nuestro Seffor, quiero y elijo más pobreza con Christo pobre que riqueza, oprobio con Christo lleno dellos que honores, y desear más de ser estimado por vano y loco por Cristo que primero fue tenido por tal, que por sabio ni prudente en este mundo" (EE 167).

El amor a Jesús pobre y humillado lleva al deseo de parecerse a él, y este deseo actúa como contrapeso tan grande al egoísmo, que puede anularlo o, al menos, compensar la aceleración que le había impreso el realismo. Por su misma dinámica, por sus ojos fijos en Jesús, el hombre situado en esta "tercera manera de libertad" ya no se curva hacia sí, sino que se curva hacia la semejanza con Jesús pobre y humillado. La indifetencia del Principio y fundamento entre "honor y deshonor, riqueza o pobreza", etc., ha sido trascendida aquí.

Pero quede claro que, si ya no se trata de indiferencia ante honor-deshonor, riqueza-pobreza etc., tampoco se trata de "más pobreza que riqueza y más oprobios que honores", sino que se trata de pobreza con Christo pobre antes que riqueza, oprobios con Cristo lleno de ellos antes que honores, etc. La referencia afectiva a Cristo es la única que pude liberar a esta postura tanto de un voluntario (que puede oscilar entre pelagiano y masoquista), como de una especie de "estética" de la propia libertad (que volvería a cerrar sutilmente al hombre sobre sí mismo), al sustituirlos a ambos por la ternura de la imitación del ser amado.

El hombre sabe ahora que no está en absoluto obligado a esa forma de "humildad" (fla gloria de Dios es la misma!). Sabe por tanto, para decirlo con el pésimo lenguaje contractual que tantas veces aplicamos los hombres a Dios, que no va a merecer nada por actuar seguin el tercer grado de humildad. Pero, de este modo, el ejercitante queda liberado del sometimiento a una exigencia exterior, moral, que sería superior a él, y que fomentaría esa casi inevitable tentación del hombre moral, que se siente siempre sobreexigido, y que vive por ello en una peligrosa y continua falta de aceptación de sí mismo.

Esta liberación todavía no se daba en la indiferencia del Principio y fundamento, a pesar de que allí la exigencia parecía menor (pero allí aún se hablaba de que el hombre "debe" o "ha de usar", etc.). Ahora, en cambio, no hay otra motivación que ese "más parecerse", esa loca gratuidad del amor que constituye —paradojicamente— la máxima perfección".

Este será el camino más seguro para la libertad. Un camino que es largo (el tercer grado de humildad no es un acto puntual) y que, aun sin saberlo, el ejercitante viene recorriéndolo desde el comienzo de la segunda semana. Su gracia 
está en que la libertad aquí no es perseguida por st misma (lo cual es la manera clásica de falsificarla), sino que viene dada "por afladidura", como ocurre con todas las dimensiones que el hombre más necesita para ser él.

De este modo intenta salvar san Ignacio que, cuando el hombre actue "más con realismo que con utopía", no lo haga en secreta defensa o en interés propio. sino porque aquel realismo es lo mejor para el reino en aquella situación concreta. Así intenta resolver Ignacio el dificilísimo problema de las mediaciones.

\section{Vuelta al realismo}

En la práctica no siempre es fácil saber, como ya he dicho, cuándo se da "igual gloria de la divina majestad", ni cuando una pobreza o una humillación son exactamente las de Cristo pobre y humillado. La historia de la espiritualidad puede testificar de bastantes errores y de algunas locuras en este punto. Por eso, san Ignacio, sorprendentemente, no acaba esta meditaciónn concretándola en ninguna lista o programa de acciones o de renuncias particulares, sino que la concreta en "pedir que el Señor Nuestro le quiera elegir en esta tercera mayor y mejor humildad" ( $E E$ 168). La oración intensa y seria sobre este punto debe ser suficiente para contrapesar el peso del realismo sobre la afectividad. Por eso hemos insistido a lo largo de todo este artículo, en que el tercer grado de humildad no es necesariamente un camino de acción, pero sí debe ser un camino de libertad. Quizás incluso —al igual que decía del martirio la primitiva Iglesiano es un camino para ser buscado ostentosamente, sino para ser pedido y recibido como gracia cuando le sobreviene a uno. Y, aunque ello parezca poco, sólo queda recomendar al ejercitante que no deje de hacer intensamente esa petición con que concluye la nota final de san Ignacio. Porque curiosamente (y muchos podrían avalar aqui mi propio testimonio), es una oración que no deja de ser oída.

En cambio, sí que es importante no hacer concreciones escrupulosas o raquiticas del tercer grado de humildad, que lo buscan en "la menta y el comino", porque es la mejor manera de ignorarlo en "la justicia y la misericordia" (ver Mt 23. 23). Así, para poner un ejemplo: se puede discutir razonablemente si no era igual gloria de Dios que monseñor Romero hubiese seguido viviendo, dada su capacidad de influjo y la necesidad de su pueblo. Pero, para que siguiera viviendo, habria hecho falta una protección oficial que el gobiemo le ofreció, y que él rechazo "porque su pueblo no disfrutaba de esa protección". En este afán de parecerse al pueblo pobre y maltratado hay un claro deseo de parecerse a Cristo, de quien los pobres son sacramento y vicario. ${ }^{2}$ Aquí tenemos un caso bien claro del tercer grado de humildad, que se prolonga en la decisión de Ignacio Ellacuría de regresar a San Salvador en noviembre de 1989, por razones idénticas a las de monseñor Romero, y para resultar asesinado tres días después. La libertad que suponen ambas decisiones habla por sí sola: tanto que es comprensible el 
comentario de una presentadora de televisión española, al referirse a otra decisión parecida: "realmente, son de otra pasta". Pero no es la pasta, sino la libertad lo que es diferente.

Y ahora sólo nos queda una breve observación final, para mostrar un poco mejor el papel que juega Jesucristo en el campo del hombre hacia esa libertad. Papel que viene marcado por los tres objetivos que señala Ignacio para la segunda, tercera y cuarta semanas de los Ejercicios.

\section{La cristología de la libertad}

Esos objetivos vienen dados por la petición de la segunda semana, y por dos consideraciones que enmarcan las meditaciones de la tercera y la cuarta. La petición es, como ya es sabido, "conocimiento interno del Señor" (EE 104). Y los marcos de reflexión son consideración de que "la Divinidad se esconde" (196), y la mirada al "officio de consolar del Resucitado" (224). La petición de la segunda semana incluye, por supuesto, las peticiones de las otras dos (dolerse con Cristo y alegrarse con él) porque sólo en la comunión de dolor y gozo el conocimiento se hace interno, al realizarse como comunión. Pero precisamente por eso no basta con analizar sólo las peticiones, y hemos de buscar la particularidad de objetivos de las otras dos semanas, en las observaciones ya indicadas.

Pues bien, entre esas tres expresiones citadas de los Ejercicios (ns. 104, 196 y 224) hay una dialéctica interna que las unifica, por lo que no parece que puedan mirarse como tres consejos dispersos entre otros muchos. Esto es lo quisiéramos mostrar para concluir.

\section{El conocimiento interno}

El conocimiento interno presupone la historia externa. Y esa historia, más allá de su infinita gama de anécdotas, esta hecha de divinidad escondida y de opción redentora o consoladora. Esta es una de las cosas que el ejercitante más tiene que aprender, porque el camino de seguimiento de Jesús es, sobre todo, ese camino del que El es "Autor y consumidor" (Heb 12, 2): el camino de la fe.

Pero el conocimiento interno no solamente descubre esas claves unificadoras de la aparente dispersión de lo real, sino que - sobre todo- reconoce en Jesús lo que yo suelo llamar "transparencia de la Misericordia": ${ }^{3}$ la decisión de convertir la propia vida en presencia de la salvación de Dios, desde esta realidad aparentemente sin Dios. El consejo ignaciano de contemplar "mirando las personas" tiene aquí una excelente función pedagógica, dado que las personas son las que sitúan cada escena evangélica en esta misma realidad nuestra, por cuanto sus sicologias son como las nuestras, sus reacciones son como las nuestras.

Permítaseme un ejemplo de eso último: pruébese hacer un estudio de la psicología de algunos personajes que aparecen en el capítulo 7 de Lucas (el 
centurión, la generación de Jesús, la pecadora...) a partir de pinceladas que suministra el evangelista. $Y$ se verá qué fácil resulta adivinar su sicologías, y qué nuestros son todos aquellos rasgos.

\section{La divinidad que se esconde}

La divinidad se esconde en el destino de Jesús. Y se esconde porque antes se había hecho casi perceptible en la interpelación y llamada de Jesús a la novedad humana. Pero se esconde de una manera que san Ignacio formula con su elementalidad desesperante: "cómo podría destruir a sus enemigos y no lo hace" y consiguientemente "deja padescer al hombre Jesús" (EE196).

Pero en esa elementalidad está el enorme misterio de la "no violencia" de Dios y de la libertad del hombre. El misterio de que, en unos seres llamados a ser libres y autores de sí mismos, Dios sólo puede hacerse presente como llamada, y como llamada del Amor, y como llamada que puede ser desoída e ignorada.

Por eso, la divinidad escondida no habla simplemente de la ausencia de Dios en lo real, sino en nuestra experiencia de lo real. En efecto, si luego se nos recomienda "mirar el officio de consolar que Cristo nuestro Senfor trae" (EE 224), es simplemente como un reconocimiento elemental de que esta realidad es desconsolada.

\section{El oficio de consolador}

También sobre este punto recomienda algo san Ignacio, a saber: que se contemple "comparando cómo unos amigos suelen consolar a otros" (224). El consuelo de la amistad es efectivamente nuestra mejor fuente de libertad, nuestro mayor signo o sacramento de una posible redención y sentido, en esta realidad desconsolada. Sin los parajes casi trascendentes que se atisban en lo mejor de la relación humana (y que resultan tan serios que el hombre no puede resistir el volver a asomarse hacia ellos a pesar de sus fracasos en relaciones anteriores), el escondimiento de la divinidad se impondría y, con él, también el eclipse de libertad: porque la aventura grandiosa de la libertad necesita echar raices en alguna apertura a una trascendencia gratificante. ( $Y$ un único ejemplo: ¿cuántas veces y con qué profunda ilación se ha dicho ya que la cultura del primer mundo, después de haber hablado mucho tiempo de muerte de Dios, está ahora hablando obsesivamente, obstinadamente, de muerte del hombre?)

\section{Conclusión}

De este modo, nuestras tres pinceladas cristológicas: conocimiento interno del Sef̂or, escondimiento de la divinidad y "oficio de Consolador", constituyen un proceso de tesis, antitesis y síntesis, en el que la libertad fundada cristológicamente puede empezar la liberación de sí misma a través de su aparente nega- 
ción".

Pero, a su vez, esta dialéctica no hace más que continuar la otra dialéctica anterior que iba del Principio y fundamento a la segunda semana (indiferenciapecado-posición cristológica de la libertad en el tercer grado de humildad), y que habiamos descrito en las dos primeras partes de este artículo (la tesis y antítesis en la parte I, y la síntesis en la parte II).

La cristología de la libertad constituye pues, para el homo viator una dialéctica inacabable.

\section{Notas}

1. La crítica más seria y más radical que conozco, es la que hace J. L. Segundo a toda la teología del Principio y fundamento y de la primera semana que, para el hablan de Dios de manera sólo "religiosa" o filosófica, y se ven contradichas por el resto de los Ejercicios. (Cf. El hombre de hoy ante Jesús de Nazaret, Madrid, 1982, II, 671-770).

Es posible que sea sí. Y yo comparto al menos la actitud de este autor, cuando argumenta que, si nos es lícito vg. criticar seriamente a un genio como Orígenes ¿por qué va a ser un "tabú" el nombre de Ignacio de Loyola? Por tanto, en mi texto no se trata tanto de una reivindicación a ultranza de la teología ignaciana, cuanto de sugerir que es posible otra lectura del comienzo de los Ejercicios Espirituales y que esta otra lectura, si bien es menos conforme con la materialidad del lenguaje (Ignacio no disponía más que del lenguaje de su época), está en cambio mucho más en consonancia con la cristología global de todos los ejercicios.

De ser cierta esta otra lectura, el verdadero origen de la teología que Segundo critica no estaría tanto en san Ignacio mismo, cuanto en la tradición teológica posterior de la contrarreforma. Lo que nadie podrá negar a J. L. Segundo es que los Ejercicios han sido leídos muchas veces de la manera que él combate; y que esa lectura es teológicamente nefasta' la mentalidad de la "prueba a pasar": llevó fatalmente a la religión del miedo y (consiguientemente también) a la religión del subterfugio, para escapar a ese miedo. La materialidad de las obras valía más que el amor y el corazón del hombre. $Y$ a esa teología conviene recordarle unas palabras mucho más antiguas de san Agustín:

"El que no peca por miedo al castigo es un enemigo de la bondad. Será amigo de ella cuando no peque por amor a la bondad. Y entonces es cuando de veras temetá pecar. Pues el que terne al infiemo no tiene miedo de pecar sino de quemarse. El que tiene miedo de pecar es el que aborrece al pecado como al infierno. $Y$ este es el verdadero temor del Señor, puro y duradero. Mientras que el otro es un temor angustiado que no tiene cabida en el amor; por eso el auténtico amor se lo carga". (Carta I45 a Atanasio, BAC, OC, Xi 192.)

Sobre la presencia del miedo y de la "teología de la prueba" en la epoca postridentins, remito al conocido libro de J. Delumeau, Le péché at la peur. En todo caso, lo que habría que decir - con las palabras de san Agustín- es que esa Iglesia 
del miedo estuvo durante siglos tratando de formar no hombres "buenos", sino hombres jinmorales!: "enemigos de la bondad"... Claro que, por suerte, el Espíritu no se sujetó a ella

2. "A mi me hacen un inmenso honor cuando me rechazan, porque me parezco un poquito a Jesuctisto, que también fue piedra de escándalo". Así predicaba Mons. Romero el 31 de diciembre de 1979. Y nótese cómo el acercamiento a Jesucristo ("me parezco un poquito") llega a convertir en gratificante ("inmenso honor") la dura experiencia del rechazo.

3. Remito a mis "Notas sobre la experiencia espiritual de los Ejercicios de san Ignacio". En Este es el Hombre, 3a. ed. Madrid, 1986, 176-201.

4. Reencontramos aquí la misma dialéctica descubierta en la cristología al hablar de "la realidad como Absoluto, la realidad como Maldición, y la realidad como Promesa". Cf. La Humanidad Nueva, 7a. ed. Madrid, 1987, cap. 15. 